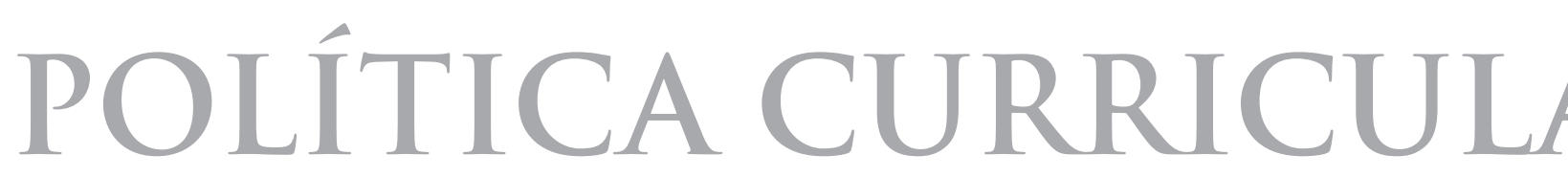
RELAÇÕES RACIAIS: INFLEXÕES PRELIM NAS PRODUÇÕES DA A 


\section{POLÍTICA CURRICULAR E RELAÇÕES RACIAIS: INFLEXÕES PRELIMINARES NAS PRODUÇÕES DA ANPED}

\section{RAQUEL AMORIM DOS SANTOS}

UNIVERSIDADE FEDERAL do PARÁ, BELÉM, BRASIL

\section{ROSÂNGELA MARIA DE NAZARÉ BARBOSA E SILVA}




\section{POLÍTICA CURRICULAR E RELAÇÕES RACIAIS: INFLEXÕES PRELIMINARES NAS PRODUÇÕES DA ANPED}

Resumo

Este estudo analisa artigos científicos publicados nos Anais das (Reuniões Anuais $\left(25^{a}\right.$ a $\left.34^{a}\right)$ da Associação Nacional de Pós-Graduação e Pesquisa em Educação (ANPED/GT-21), localizados na área das Relações "Raciais" e Educação, relativas ao período de 2000 a 2011. Os resultados revelam que as pesquisas sobre Educação e Relações "Raciais" impulsionam novos sentidos e possibilidades de uma construção democrática que tenha por base o reconhecimento das diferenças étnico-raciais que se impõem pela necessidade de políticas afirmativas, visando assegurar condições de acesso e tratamento igualitário para os negros em todas as esferas da vida social.

Palavras-chave: política curricular, relações "raciais”, ANPED

\section{CURRICULUM POLICY AND "RACIAL" RELATIONS: PRELIMINARY INFLECTIONS IN THE ANPED PRODUCTIONS}

Abstract

This study examines papers in the Proceedings of Annual Meetings (25th to 34th) of the National Association of Graduate Studies and Research in Education (ANPED/GT-21), published in the section of racial relations and education in the period 2000-2011. The results reveal that the research on education and racial relations drive new meanings and the possibility of a democratic construction that builds on the recognition of ethnic and racial differences, which is imposed by the need for affirmative action policies, aiming at ensure access and equal treatment for persons of African descent in all spheres of social life.

Keywords: curriculum policy, "racial” relations, ANPED

\section{LA POLITIQUE DES PROGRAMMES ET DES RELATIONS "RACIALES": INFLEXIONS PRELIMINAIRES DANS LES PRODUCTIONS ANPED}

Resumé

Cette étude examine les productions figurant dans les Actes de la réunion annuelle (25e-34e) de l'Association nationale des études supérieures et de la recherche en éducation (ANPED/GT-21), dont la production scientifique est située dans le domaine des relations "raciales" et de l'éducation pour la période 2000-2011. Les résultats révèlent que la recherche sur l'éducation et les relations "raciales" motivent des nouvelles significations et possibilités d'une construction démocratique qui s’appuie sur la reconnaissance des différences 
etnico-raciales qui s’imposent par la nécessité de politiques de discrimination positive, qui visent à assurer des conditions d'accès et l'égalité de traitement pour les Noirs dans toutes les sphères de la vie sociale.

Mots-clé: politique du programme, relations "raciales", ANPED

Endereço da primeira autora para correspondência: Conjunto Cidade Nova IV, SN 17, Residencial Araçari, Bloco B, Apt. 303 - CEP 67133 000, Ananindeua-PA, Brasil. E-mail: rakelamorim@yahoo.com.br 


\section{INTRODUÇÃO}

Este artigo analisa os artigos da Associação Nacional de Pós-Graduação e Pesquisa em Educação (ANPED), no Grupo de Trabalho Afro-Brasileiros e Educação (GT-21) , cuja produção científica está localizada na área das Relações Raciais e Educação, com ênfase na educação dos Afro-brasileiros. Especificamente, neste trabalho nos deteremos no levantamento das produções encontradas nos Anais das Reuniões Anuais $\left(25^{\mathrm{a}}\right.$ a $\left.34^{\mathrm{a}}\right)$, relativas ao período de 2000 a 2011, as quais apresentam como ênfase temática em seu conjunto de textos: a política educacional, a politica curricular, as politicas de acooes afirmativas, o Movimento negro e a Lei no 10.639/2003. Os resultados revelam que as pesquisas sobre Educação e Relações Raciais foram ampliadas na última década no Brasil, favorecendo a abertura de espaços de discussões e busca de alternativas para minimizar a discriminação racial e o preconceito nas escolas. Concluímos que esses estudos impulsionam o debate sobre a superação do racismo, discriminação e preconceito racial nos diferentes campos sociais.

A pesquisa analisa a Política Curricular e as Relações Raciais, duas categorias basilares no campo dos Estudos Étnico-raciais. Desse modo, utilizamos a abordagem qualitativa com aplicação de pesquisa bibliográfica (Gatti 1983). De modo adjacente, analisamos as ênfases temáticas identificadas no conjunto dos textos, tais como: Política Educacional, Política Curricular, Políticas de Ações Afirmativas, Movimento Negro e Lei $n^{\circ} 10.639 / 2003$.

A metodologia seguiu a tendência para estudos de análise de Estado da Arte, propostas por alguns estudos que fizeram em suas distintas abordagens levantamentos da produção de pesquisas, respectivamente, nas áreas de Relações Raciais e Políticas de Currículo. Procedeu-se com a análise documental dos artigos produzidos nas Reuniões Anuais da ANPED, com a seguinte sistemática: a) levantamento dos artigos; b) leitura em cada reunião, por ano, a partir das categorias elencadas anteriormente; c) produção de tabelas, nas quais se buscou detectar artigos em que a política curricular aparecia de forma explícita, bem como aqueles em que se anunciavam preocupações ou potenciais sobre política curricular e relações raciais, mas não se denominavam claramente como política curricular; e, por fim, d) análise dos trabalhos, procurando evidenciar suas implicações teóricas e práticas.

O tema abordado formou-se nas últimas décadas como um campo de estudos emergente, de interesses e posicionamentos múltiplos. Um conjunto significativo de pesquisas e trabalhos - que têm por objeto as Relações Raciais nos processos educativos, interpretados a partir de um espectro amplo de temáticas de interesse e perspectivas teórico-metodológicas pode demonstrá-lo.

A respeito disso, Gonçalves \& Silva (2000a, 2000b) também categorizaram os estudos sobre relações raciais e educação entre os anos 80 e 90, tomando por base os trabalhos apresentado na ANPED, nos quais predominavam as seguintes questões: identidades de crianças negras; estereótipos e preconceitos nos livros didáticos; identidade étnica de trabalhadores rurais; rituais pedagógicos enquanto mecanismo de discriminação racial; formação e trajetórias de professores negros e avaliação de experiências no campo da multiculturalidade. (Silva 2003, Gonçalves \& Silva 2000a, 2000b).

É importante salientar que, no presente texto, não se optou por uma relação quantitativa dos artigos, mas sim, limitou-se à análise do dialogismo discursivo evidenciado. Neste sentido, Bakhtin (2003) 
aponta que o dialogismo se mostra nas muitas vozes, criando e recriando sentidos e significados às palavras ditas e às não ditas entre locutor e interlocutor.

No levantamento geral dos trabalhos apresentados nas Reuniões Anuais da ANPED, no recorte explicitado, foram encontrados dezoito (18) trabalhos que se relacionavam à Política Curricular e Relações Raciais. Conforme Tabela 1 abaixo:

Tabela 1.

Quantidade de Publicações Anuais sobre Política Curricular e Relações Raciais (20002011), segundo a ANPED

\begin{tabular}{|c|c|c|c|c|c|}
\hline \multirow{4}{*}{$\underline{\text { Ano }}$} & \multicolumn{4}{|c|}{ FONTE DOCUMENTAL } & \multirow[t]{2}{*}{ GERAL } \\
\hline & \multicolumn{4}{|c|}{ ANPED GT-21 } & \\
\hline & \multicolumn{5}{|l|}{ REUNIÕES } \\
\hline & ANUAIS & ARTIGOS & $\%$ & Qtd. & $\%$ \\
\hline 2000 & - & - & 0 & - & 0 \\
\hline 2001 & - & - & 0 & - & 0 \\
\hline 2002 & $25^{\mathrm{a}}$ & 1 & 5,6 & 1 & 5,6 \\
\hline 2003 & $26^{a}$ & 2 & 11,1 & 2 & 11,1 \\
\hline 2004 & $27^{\mathrm{a}}$ & 1 & 5,6 & 1 & 5,6 \\
\hline 2005 & $28^{\mathrm{a}}$ & 4 & 22,2 & 4 & 22,2 \\
\hline 2006 & $29^{a}$ & 2 & 11,1 & 2 & 11,1 \\
\hline 2007 & $30^{\mathrm{a}}$ & 1 & 5,6 & 1 & 5,6 \\
\hline 2008 & $31^{\mathrm{a}}$ & 1 & 5,6 & 1 & 5,6 \\
\hline 2009 & $32^{\mathrm{a}}$ & 2 & 11,1 & 2 & 11,1 \\
\hline 2010 & $33^{\mathrm{a}}$ & 1 & 5,6 & 1 & 5,6 \\
\hline 2011 & $34^{a}$ & 3 & 16,7 & 3 & 16,7 \\
\hline TOTAL & - & 18 & 100,0 & 18 & 100,0 \\
\hline
\end{tabular}

A Tabela 1 apresenta a quantidade de produções por ano de publicação entre 2000 e 2011, de acordo com o Tipo de Fonte Documental (ANPED GT-21) e Tipo de Projeto (Artigo). Nela, verifica-se que as publicações da ANPED GT-21 foram produzidas em sua maior parte no ano de 2005, com 22,2\% do total, seguido pelo ano de 2011 , com $16,7 \%$.

Em relação ao tratamento metodológico, os estudos combinaram a pesquisa bibliográfica e análise de documentos, usando para o trabalho empírico: pesquisas apoiadas na análise de depoimento; nos estudos de um caso; nos estudos de caso do tipo etnográfico; nos estudos descritivos ex- ploratórios; nos estudos de pesquisa-ação - que fazem a análise da prática pedagógica; a história de vida; análise das práticas discursivas; e, pesquisa bibliográfica.

Um aspecto que deriva desses estudos é a identificação das técnicas mais utilizadas nas pesquisas, tais como: entrevistas, análise de documentos, observação, questionário, diário de campo, fotografias, grupo de discussão e grupo focal.

Quanto ao enfoque teórico privilegiado, nem sempre eles estavam claramente definidos, mas foi possível identificar as contribuições das Ciências Sociais, da Sociologia e da Psicologia. Ainda identifica- 
mos a abordagem qualitativa (Flick 2004), destacando-se a pesquisa no campo da etnografia (Clifford 1977) e a pesquisa sócio-histórica (Burke 2000, Le Goff 1994, Ginzburg 1989). Em menor número, vêm as abordagem fenomenológica, sociopoética e psicossocial (Moscovici 1978, Jodelet 2001).

Nesses estudos também se observou uma concentração de pesquisas sobre políticas de ações afirmativas e legislação antirracista , mesmo assim, as bases teóricas que subsidiaram as análises apontam para a referência à perspectiva crítica como base de interpretação dos dados. A referência comum foi na discussão sobre o sistema de cotas e Lei $\mathrm{n}^{\circ} 10.639 / 2003$, sendo frequentemente citados os autores: Silvério (2003), Silva \& Silvério (2003), Santos (2005), Gomes (2000, 2001), Silva Jr. (1998), Moehlecke (2000), Siss (2003), Gomes (2003, 2006, 2008), Duarte et al. (2008), Coelho (2006, 2009), Coelho \& Coelho (2008), Dias (2005) para citar alguns.

Nos estudos que partiram da perspectiva do Estado para compreender as políticas educacionais e curriculares voltadas para a temática racial, foi comum a referência de Apple (1996), Anderson (1995), Barreto (2000) e Sacristán (1998) para analisar o Estado regulador centrado nas concepções das políticas neoliberais. Mas, notamos que em relação à influência dos organismos internacionais como definidores de políticas (CEPAL/UNESCO, Banco Mundial - BM, Banco Interamericano de Desenvolvimento - BIRD, entre outros), os estudos apreciados apresentam um foco difuso, sem esclarecer de modo circunstanciado tal discussão nas pesquisas apresentadas.

Dentre os trabalhos coletados nas Reuniões Anuais da ANPED, destacamos aqueles que apresentam alguns indícios da perspectiva do Estado voltados para a temática racial, tais como: Veríssimo (2003), Gonçalves \& Silva (2005), Rodrigues (2005), Souza (2009) e Marques (2011), como veremos a seguir.

O trabalho de Veríssimo (2003) analisa as políticas do governo de Fernando Henrique Cardoso, no período de 1995 a 2002, em específico as políticas de ações afirmativas. A autora aponta que a partir da lógica da eficiência, esse governo buscou a reorganização da educação e mecanismos da avaliação de sistema, em âmbito nacional e em todas as modalidades. Acrescenta que, apesar dos avanços das políticas educacionais, ainda há desconsideração no que concerne às diferentes contribuições da diversidade brasileira.

Neste sentido, a autora argumentou que:

"o debate sobre políticas públicas de ação afirmativa na área educacional se restringiu as cotas nas universidades, o que levou ao empobrecimento da dimensão estrutural da reprodução do racismo e da dimensão política dos efeitos da política de discriminação positiva. Dentro da área educacional seria necessário propor um conjunto significativo de ações que viessem a combater de fato a reprodução do racismo nas varias dimensões dos espaços educacionais e nas suas diferentes modalidades. A ações precisariam ser coordenadas e implementadas articuladamente" (Veríssimo 2003:14).

Assim, conclui que essas "lutas tem resultado em avanços", entretanto, "caberá à educação e, particularmente aos educadores o desafio de propor ações que efetivamente possa rever o processo de exclusão da população negra dos bancos escolares" (Veríssimo 2003:14). 
A análise da política de ações afirmativas, feita neste trabalho, partiu das políticas implementadas na década de 1990, dando continuidade as demandas políticas feitas pelos organismos internacionais aos países da América Latina, visando a intensificação do acesso à educação, cujo maior desafio era a permanência e qualidade do ensino ministrado nas escolas públicas. Todavia, é justamente em virtude dessa realidade que as políticas de ações afirmativas assumem uma dimensão política e vêm se consubstanciando no debate da ordem do dia no Brasil.

O estudo de Gonçalves \& Silva (2005) refere-se sobre a questão do negro e políticas públicas de educação multicultural. As autoras tecem análise a partir de três objetivos estruturais: construção histórica do processo racial; análise das políticas educacionais na década de 1990, observando os avanços e limitações dessas propostas; e, por fim, investigação das manifestações multiculturais no processo de escolarização veiculada pelo currículo escolar.

Os argumentos trazidos pelas autoras em relação ao processo histórico das relações raciais apontam que a "resistência negra foi, por muito tempo, omitida pela escola, dando falsa imagem do negro indolente. A constatação de diferentes identidades abalou as estruturas curriculares marcadas pelo eurocentrismo" (Gonçalves \& Silva 2005:6). Sobre as políticas educacionais, as autoras sustentam que tais estão acopladas à ideologia racial, com o objetivo da manutenção de poder e subordinação que, possivelmente, tenha contaminado as Políticas Públicas Educacionais e, consequentemente, as teorias de currículo por meio de uma visão eurocêntrica centrada na seletividade de seus conteúdos.

Acerca das manifestações multiculturais no processo de escolarização, Gonçalves \& Silva (2005) evidenciam as práticas educativas emanadas do currículo oficial não têm possibilitado avanços rumo ao multiculturalismo. Nesse texto, observou-se uma frágil discussão teórica sobre a temática e a polissemia do termo multiculturalismo e suas diversas abordagens no que tange à vertente mais crítica, também denominada multiculturalismo crítico ou perspectiva intercultural crítica (Canen 1999, 2001, Canen \& Moreira 2001, McLaren 2000).

No artigo realizado por Rodrigues (2005) sobre o movimento negro, raça e política educacional, a autora examina a importância e o tratamento da categoria raça na definição de políticas educacionais, a partir da apreciação da Constituição Federal/1988 e a LDB n ${ }^{\circ} 9.394 / 96$, especialmente a Lei $n^{\circ} 10.639 / 03$. Em seu conjunto, há uma reflexão sobre como, nos campos educacionais, as culturas ocidentais são tomadas como modelo e as demais, culturas que não são oriundas deste meio, são veiculadas de forma depreciativa, pejorativa e discriminatória, visto que a história dos negros no Brasil é tratada com base no mito da democracia racial, provocando um forte prejuízo na construção identitária e cultural da população negra.

Em relação à concepção de currículo e à Lei no 10.639/2003 em consonância com o papel do Estado, tem-se o estudo de Souza (2009) que investiga as providências curriculares sugeridas pela Lei $n^{\circ}$ 10.639/2003, bem como algumas metas do Parecer CNE/CP 3/2004. Baseada nesse Parecer, a autora parte da compreensão de que o Estado tem o dever de promover políticas de reparações voltadas para a educação dos negros. No referido estudo, currículo é concebido como uma política cultural que "leve em consideração culturas diferenciadas daquelas que costumamos considerar: a cultura pautada, predominantemente, em valores europeus" 
(Souza 2009:5) .

Nesta concepção subjaz um campo cultural no qual o conhecimento, o discurso e o poder interseccionam-se de maneira a produzir práticas historicamente específicas de regulação moral e social. Neste sentido, as experiências são produzidas, contestadas e legitimadas na dinâmica da vida escolar cotidiana. Por fim, a autora conclui que as "escolas de Ensino Fundamental deveriam ser o local onde a igualdade de oportunidades fosse plenamente exercida, (...) privilegiam as propostas curriculares que reproduzem a ideologia cultural dominante" (Souza 2009:13). Essa reflexão pode ser complementada pelas as postulações de Giroux (1997), ao mencionar que:

"As escolas não são de forma alguma ideologicamente inocentes, $\mathrm{e}$ nem simplesmente reproduzem as relações e interesses sociais dominantes. Elas, (...) de fato exercitam formas de regulação moral e políticas intimamente relacionadas com as tecnologias de poder" (Giroux 1997: 124).

Na visão de Giroux (1997), a escola não é um elemento neutro, inocente, estático, desinteressada das relações de poder, mas estabelece as condições sob as quais alguns indivíduos e grupos definem os termos pelos quais os outros vivem, resistem, afirmam e participam da construção de suas próprias subjetividades. A escola também materializa a regulação (moral e política) das formas de conhecimento que constituem os currículos formais, bem como das relações sociais escolares que penetram tanto o corpo como a mente dos alunos.

As escolas constituem-se como instituições históricas e culturais que sempre incorporam interesses ideológicos e políticos. Não raro, a forma como atribuem significados à realidade é fortemente con- testada por diferentes indivíduos e grupos. Assim, elas são terrenos ideológicos e políticos a partir dos quais a cultura dominante "fabrica" suas "certezas" hegemônicas, mas são também lugares onde grupos dominantes e subordinados se definem e se reprimem mutuamente em uma luta e um intercâmbio incessante, em resposta as condições sócio-históricas "propagadas" nas práticas institucionais, textuais e vivenciais que caracterizam a cultura escolar e a experiência professor/aluno dentro de determinados tempo, espaço e local (Giroux \& McLaren 2009).

O artigo de Marques (2011) versa sobre a manifestação do preconceito e da discriminação racial na trajetória dos alunos negros bolsistas do PROUNI, especificamente nos cursos de Direito e Pedagogia noturno, do Centro Universitário de Campo Grande no Mato Grosso do Sul. Neste estudo analisa a inserção de alunos negros na Educação Superior - bolsistas do PROUNI - e problematiza a presença do duplo preconceito e da discriminação racial no espaço acadêmico. Assim, a autora afirma que:

$$
\begin{aligned}
& \text { "Não se pode tratar a questão ra- } \\
& \text { cial como elemento secundário, } \\
& \text { destacando apenas a problemática } \\
& \text { econômica, ou seja, o debate sobre } \\
& \text { as desigualdades raciais no Brasil, } \\
& \text { não se baseia apenas na possibilida- } \\
& \text { de de ascensão social da população } \\
& \text { negra, pois ainda há uma grande } \\
& \text { dificuldade da sociedade brasileira } \\
& \text { em assumir a questão racial como } \\
& \text { um problema que necessita ser en- } \\
& \text { frentado" (Marques 2011: 15). }
\end{aligned}
$$

Associada a essa discussão da inserção de alunos negros na Educação Superior, verificamos também um intenso debate sobre as políticas implementadas no governo "democrático" capitalista que atendam dignamente as reivindicações da popula- 
ção negra. Entendemos que a positividade aparente, porém concreta dessas políticas, possui, a um só tempo, a sua improbidade - na medida em que acenam para a possibilidade de acesso a Educação Superior; em contrapartida, não viabilizam Políticas de Estado, estruturais e universais articuladas que possam contribuir para solucionar as múltiplas desigualdades que predominam na sociedade brasileira.

Além dessas temáticas centradas na perspectiva do Estado, consideramos importante analisar os estudos que abordam a perspectiva das políticas para a igualdade racial com destaque as Ações Afirmativas, as quais são entendidas como políticas públicas (e privadas) voltadas para a concretização do princípio constitucional da igualdade material e neutralização dos efeitos da discriminação racial, de gênero, de idade, de origem nacional e de compleição física (Gomes 2001) ou ainda como uma "política pensada para a superação do preconceito e da discriminação" (Coelho \& Coelho 2008: 21).

O levantamento dos trabalhos que abarcam a temática de políticas de açoes afirmativas, no que diz respeito aos anais das

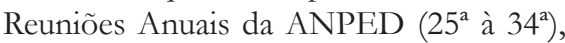
totalizam nove (9) títulos.

Em seu artigo, Siss (2002) apresenta algumas considerações sobre Políticas de Ações Afirmativas e Educação dos afro-brasileiros. $\mathrm{O}$ autor expõe as desigualdades de acesso à educação, de permanência em instituições escolares em quaisquer níveis, de realização. Revela que as trajetórias escolares de alunos Afro-Brasileiros e brancos, quando comparadas, são diferenciadas e sempre em detrimento dos Afro-Brasileiros. Adverte que há de se levar em consideração o contexto das relações sociais em que tais políticas estão inseridas, para tentar evitar se operar com reducionismos drásticos, tornando simplistas ou superficiais tais análises.

Após realizar um estudo comparativo entre Brasil e Estados Unidos, o autor conclui que "não se elimina privilégios históricos impunemente. $\mathrm{Na}$ maioria das vezes, um alto preço é cobrado. Felizmente, o resultado desse pagamento exigido, acredito ser a democratização da sociedade" (Siss 2002:12). Esse estudo permite desvendar, em parte, tanto o discurso oficial do Estado Brasileiro, quanto à luta dos movimentos negros por Políticas de Reparações, de Reconhecimento e Valorização da população dos Afro-Brasileiros, situando a especificação do sujeito de direito, que passa a ser visto em sua peculiaridade e particularidade.

Nesta direção, o artigo de Veríssimo (2003) sobre Educação e desigualdade racial: políticas de ações afirmativas faz uma breve contextualização das políticas na reorganização da educação a partir da conjuntura dos anos 1990. A autora avança no sentido de apresentar no campo educacional a luta dos movimentos sociais, especialmente os que tratam da denúncia de discriminação racial no trabalho, entre os quais destaca: Central Única dos Trabalhadores (CUT), Grupo de Trabalho para Eliminação da Discriminação no Emprego e na Ocupação (GTEDEO), Instituto Sindical Interamericano pela Igualdade Racial (INSPIR).

A partir das iniciativas desses movimentos, tem-se como resultado positivo a elaboração do Mapa da População Negra no Mercado de Trabalho nos anos de 1999, feito pelo Centro de Estudos das relações de Trabalho e Desigualdades (CEERT). Assim, conclui que todas as medidas têm como eixo central "instituir cotas para negros e mulheres nos preenchimentos dos cargos de confiança, bem como exigir das empresas contratadas na prestação de serviços a inserção, em seus quadros funcionais, de um percentual de negros e mulhe- 
res" (Veríssimo 2003:11).

Veloso (2005) relata a experiência da Universidade Federal de Montes Claros (UNIMONTES) sobre o sistema de reserva de vagas em seus cursos de graduação e discute formas de acesso ao Ensino Superior. Aponta que, a partir da aplicação de questionários, a "a instituição de cotas na UNIMONTES não foi gestada, pensada e proposta por sua comunidade universitária" (Veloso 2005:2). Pela análise das concepções reveladas nos discursos dos professores, a autora verificou que "para muitos, a resistência em relação às cotas esta articulada à crença de que o processo, em si, é promotor da discriminação social e racial" (Veloso 2005:14). Por último, chama atenção para a implementação de políticas de cotas na Universidade, mostrando que as Universidades Públicas devem envolver os diferentes segmentos (professores, funcionários técnico-administrativos, acadêmicos cotistas e não-cotistas), sem isso será impossível uma verdadeira transformação de ações, concepções, representações acerca do racismo historicamente constituído no Brasil.

Miranda (2005) apresenta narrativas sobre cotas em jornais, ressaltando a probabilidade de fracasso por parte dos ingressantes contemplados pelo sistema de reservas de vagas nas universidades públicas. Faz uma análise das manifestações contrárias às cotas divulgadas em dois jornais $(O$ Globo e Jornal do Brasii). Para tanto, tece considerações acerca da Pedagogia da mídia na perspectiva das políticas de branquidade, com base na discussão teórica de identidade branca proposta por Liv Sovic (2004) e Vron Ware (2004). Este trabalho revela que "a re-interpretação das narrativas sobre cotas traduz uma necessidade de desvelarmos, sobretudo, em que medida os jornais trabalham para perpetuar seu lugar de reprodutor, por exemplo, de políticas de branquidade, por porta voz de grupos eurodescendentes" (Miranda 2005:4). No cômputo geral da análise, a autora evidencia que:

"A gravidade das desigualdades raciais está sendo rechaçada na construção do consenso sobre cotas e, os jornais reeditam um tipo de controle social que tem, como foco a não-agência dos grupos subalternizados". Portanto, considera a autora que "[...] é necessário examinarmos o jogo retórico que desqualifica a consistente produção teórica sobre o racismo e seus desdobramentos no Brasil" (Miranda 2005:12).

A crítica realizada pela autora acerca das narrativas sobre cotas veiculadas em jornais, emissoras de televisão e instrumentos midiáticos tem força para convencer e forjar discursos hegemônicos, em que as "branquidades inquestionadas marcam esses territórios por processos de colonização e têm orientado culturalmente as estruturas sociais" (Miranda 2005: 5). Em síntese, é possível ver a construção da cultura branca como modelo, justificando assim sua dominação, por meio das ressignificações de lutas e reivindicações dos movimentos negros em prol de políticas de ações afirmativas para o enfrentamento e desconstrução da concepção essencialista nos campos sociais, inclusive o midiático.

Compreendemos, com o apoio de Coelho (2009), que o silêncio é um agravante no processo de respeito e entendimento das diferenças raciais, consequentemente na luta contra as visões essencialistas. Neste sentido, a autora nos diz que:

"A cor no Brasil é como aquele sujeito que está só de corpo presente: ele está ali, mas ninguém vê, ninguém nota, ninguém se interessa. 
Todos sabem que está, mais não há manifestação, reconhecimento, valorização ou coisa que o valha que indique que aquele sujeito está vivo, é importante é querido" (Coelho 2009:162).

Em artigo publicado na ANPED, Coelho (2007) ainda nos lembra das definições de beleza ou de sua falta, atribuídas ao branco como modelo, cuja "cor da pele, índice de destaque, continuava sendo índice de distinção na escola - quanto mais negra, menos importância" (Coelho 2007:11).

$\mathrm{Na}$ esfera do Ensino Superior, Menin e Shimizu (2006) fazem uma análise das representações sociais de diferentes políticas de ações afirmativas para negros, afrodescendentes e alunos de escola pública na Faculdade de Ciências e Tecnologia (UNESP). Para estas autoras, tais ações tendem a construir uma identidade confusa entre os alunos negros, pois esses são vistos como oportunistas:

"os alunos negros de faixa salarial maior foram os mais cépticos em relação à capacidade dos beneficiários das medidas. Esse resultado parece evidenciar o fenômeno de 'branqueamento', em que os negros passam a se identificar com uma ideologia dos brancos" (Menin \& Shimizu 2006:18).

De forma semelhante, podemos verificar que as considerações deste trabalho se aproximam dos resultados empreendidos no estudo de Miranda (2005) acerca da compreensão da política de branquitude como discurso hegemônico que tem orientado culturalmente as estruturas sociais:

"identificada à pertinência social e racial dos participantes da pesqui$\mathrm{sa}$, os estudantes de menor faixa salarial e negros foram mais favorá- veis às políticas mais agressivas do que os demais, mostrando que um posicionamento favorável às cotas é, ainda, restrito apenas ao grupo beneficiário" (Miranda 2005:18).

Já os artigos de Jesus $(2008,2009)$ abordam sobre as microações afirmativas no cotidiano das escolas públicas, a partir das narrativas de três professoras da rede Pública do Rio de Janeiro. Para a autora, as microações afirmativas empreendidas nas narrativas dessas professoras são "ações comprometidas com a transformação da realidade de opressão com a qual convivem crianças e jovens negros em nossas escolas públicas" (Jesus 2008: 15). Neste sentido, no artigo acerca das Práticas pedagógicas, evidenciam-se microações afirmativas cotidianas, destacando "as práticas pedagógicas de caráter instituinte são micro-ações afirmativas cotidianas" (Jesus 2008:2), portanto as incursões aproximam-se ao "desvelamento da realidade, comprometidas com o conbecimento-emancipação, puderam dar início a um processo de superação da condição de oprimidas, passando a proferir suas próprias palavras mundo e propondo ações emancipatórias no cotidiano escolar" (Jesus 2008:15).

Tomain \& Lima (2010), em seu artigo, analisam as representações sociais de professores do Ensino Médio sobre cotas para negros na Universidade e expõem duas imagens do processo de objetivação: "a invisibilidade do outro" e "igualdade". Segundo as autoras, essas representações sociais parecem se ancorar em construções sociais que, no Brasil, historicamente associam-se à discriminação e prejuízos causados aos negros, o que supõe necessidade de reparações. Assim, elas concluem que as representações sociais de professores apoiam-se no núcleo figurativo do mito da democracia racial amparado pela crença da meritocracia, cotas para pobres, omis- 
são do racismo na escola, o que implica na construção positiva da identidade negra.

No trabalho de Barbosa \& Lima (2011), as ações afirmativas aparecem em um Programa de Integração e de Inclusão Étnico-racial (PIIER) da Universidade do Estado de Mato Grosso (UNEMAT), especificamente no curso de Enfermagem. Nesse Programa analisam a percepção de docentes, discentes (cotistas e não-cotistas). Os resultados demonstram que "os conceitos que ainda estão enraizados nos sujeitos pesquisados refletem atitudes discriminatórias mesmo que de forma inconsciente, contribuindo para sua subjetivação" (Barbosa \& Lima 2011:14). Assim, para autoras:

"a Universidade como espaço de convivência cientifica e intelectual, não pode conviver ou aceitar atitudes racistas, preconceituosas e/ou de discriminação. Possibilidades de superação desses (pré) conceitos somente poderão ocorrer a partir das mudanças de concepções dos sujeitos, o que, pode acontecer pela educação e/ou reeducação dos mesmos" (Barbosa \& Lima 2011:14).

Essa constatação coloca na ordem do dia a premência de políticas de açoes afirmativas para democratizar o acesso e permanência no Ensino Superior dos grupos fragilizados econômica e socialmente (e não apenas os negros, como é o caso das cotas). Assim, é importante perceber que, na maioria dos artigos sobre açôes afirmativas, as pesquisas se encaminham para a superação da compreensão distorcida das relações sociais, particularmente das relações étnico-raciais e, também, das que se desencadeiam no interior do Ensino Superior, fomentadas pelo mito de que no Brasil se viveria a experiência de uma democracia racial sob os auspícios de uma sociedade hegemônica.

Ainda há um conjunto de textos que abordam a perspectiva das políticas para a igualdade racial com destaque para aqueles que tratam da Lei $n^{\circ} 10.639 / 2003$, a qual apresenta uma trajetória singular, pois surge da demanda do movimento negro pela formulação de Políticas Afirmativas que dirimissem as enormes desigualdades que distinguem os brasileiros pela cor da pele (Brasil 2004, Coelho \& Coelho 2008, Rocha 2008).

Rosa (2006), no artigo Os professores de Arte e a inclusão: o caso da Lei no 10.639/2003, buscou resgatar junto aos docentes a existência de práticas de ensino em consonância com os pressupostos da referida lei. De modo geral, fez uma análise do conceito de identidade, tomando-a relacional, construída a partir de elementos simbólicos e sociais dentro do contexto onde se insere o sujeito, sendo então externa ao mesmo, podendo ser construída tanto com elementos negativos, como positivos.

Com base em Woodward (2000), a autora concebe a identidade brasileira como um processo relacional, na medida em que o sujeito que se identifica e o faz por aspectos simbólicos relativamente a outras identidades. Aspectos que são símbolos para um grupo podem levar a uma identidade. Ainda segundo a autora, dentro do aspecto de uma identidade nacional, poderá haver diferenciações internas, de classe e de gênero: "Os aspectos psíquicos também fazem parte da percepção da identidade, juntamente com as dimensões sociais e simbólicas" (Woodward 2000:4).

Em suas conclusões, a autora ressalta dois aspectos: a) o estranhamento em relação aos desafios postos na realidade, deslocando algumas vezes o objeto de estudo; b) a singularidade e os múltiplos olhares da realidade circundante. Por vezes, o próprio 
debate acerca dos resultados da pesquisa no contexto da escola pode favorecer a análise crítica do trabalho realizado. No caso da investigação sobre a própria prática, o registro atento das atividades construídas cotidianamente é fator fundamental para o rigor da pesquisa. Esta atividade ajuda na ampliação do compromisso do professor com sua ação pedagógica.

O artigo de Pereira (2007) discute entraves entre educadores, mesmo alguns mais engajados na implementação da Lei - assumidamente agentes da Lei; desde a ingenuidade com que, muitas vezes, assimilamos temáticas, conceitos, conteúdos. Identificou duas fontes desses entraves: 1) a dificuldade para lidar com algumas questões básicas, como o conceito de História e Cultura Afro-Brasileira e 2) a articulação de conteúdos capazes de dar conta da sua complexidade.

Ao abordar as questões conceituais sobre Lei, Pereira (2007) percebe que ainda é um conceito em construção. $\mathrm{O}$ exame do autor foi feito com base em quatro aspectos levantados: a) aspectos políticos dessas trajetórias; b) as caracterizações e sentidos das manifestações culturais e religiosas; c) questões de identidade; d) soluções pragmáticas para o enfrentamento do preconceito e da discriminação racial.

Neste trabalho verifica-se um descompasso em relação à implementação da Lei, pois se de um lado existe a Lei como instrumento jurídico a ser efetivado na escola, por outro, tem-se as dificuldades e o despreparo dos profissionais de educação que não tiveram nenhum tipo de orientação pedagógica para tratar da questão racial. Assim, Pereira (2007:16) conclui que a "práxis dos educadores é uma instância de responsabilidade para a implementação da Lei".

Souza (2011), abordando essa mesma perspectiva, apresenta dois artigos em que discute a Lei $n^{\circ}$ 10.639/03 em escolas públicas do Município do Rio de Janeiro, objetivando trazer subsídios para a implementação da Lei em consonância com a proposta curricular veiculada pela escola pública de Ensino Fundamental. Assim, afirma que "o silêncio sobre a problemática racial ainda faz parte da postura de alguns professores, revelando que o currículo nunca é uma proposta neutra de conhecimentos" (Souza 2011:1). As considerações finais apresentadas pela autora direcionam-se ao estabelecimento da obrigatoriedade do ensino de história e cultura afro-brasileira e africana, no qual o Estado cumpre, em parte, a demanda da população negra por reconhecimento, valorização e afirmação de direitos. Em parte porque não basta promulgar a Lei, sobretudo, é preciso implementá-la, dando condições aos estabelecimentos de ensino para operacionalizá-la. Evidentemente, tal operacionalização exige um esforço maior do poder público no que se refere à formação de professores, em serviço ou não. Essa é uma das dificuldades na aplicação da Lei.

\section{CONCLUSÕES PRELIMINARES}

Nesse conjunto de artigos que engloba as discussões acerca das políticas educacionais, especialmente as políticas para a igualdade racial: Ações Afirmativas e Lei $n^{\circ}$ $10.639 / 2003$, as inflexões são as mais diversas, algumas demonstram maior fundamentação teórica e apresentam reflexões mais aprofundadas sobre as políticas educacionais voltadas para a população negra. Outras se limitam a expor o que foi feito e a tecer breves comentários sobre os objetivos atingidos.

De modo geral, surgem algumas categorias estruturais como: racismo, desigualda- 
de racial e discriminação direcionada à população negra e que impregna a sociedade brasileira. No que diz respeito à educação, infelizmente, a situação não é diferente, entretanto, consideramos que a educação escolar em uma perspectiva antirracista, não pode ser a transmissão acrítica dos conhecimentos que o Estado e as demais instituições dominantes consideram legíti- mas, seja por meio do currículo, seja por meio das práticas instituintes na escola.

Assim, a análise do corpus dos anais da ANPED proporcionou a síntese dos resultados da pesquisa retratados no Quadro 1 abaixo:

Quadro 1.

Síntese dos resultados de pesquisas sobre Política Curricular e Relações Raciais

\begin{tabular}{|c|c|c|}
\hline & Agentes Enunciadores & Enunciados \\
\hline $\begin{array}{l}25^{\mathrm{a}} \text { Reunião Anual } \\
26^{\mathrm{a}} \text { Reunião Anual } \\
30^{\mathrm{a}} \text { Reunião Anual } \\
34^{\mathrm{a}} \text { Reunião Anual }\end{array}$ & $\begin{array}{l}\text { Siss (2002), Veríssimo (2003), } \\
\text { Pereira (2007), Souza (2011). }\end{array}$ & $\begin{array}{l}\text { Políticas de caráter reparatório, } \\
\text { compensatório ou de ação afirmativa. }\end{array}$ \\
\hline $\begin{array}{l}27^{\mathrm{a}} \text { Reunião Anual } \\
28^{\mathrm{a}} \text { Reunião Anual }\end{array}$ & $\begin{array}{l}\text { Veríssimo (2004), Gonçalves } \\
\text { \& Silva (2005), Rodrigues } \\
(2005) .\end{array}$ & $\begin{array}{l}\text { Política Educacional articulada à exclusão } \\
\text { educacional e racial. }\end{array}$ \\
\hline $\begin{array}{l}28^{a} \text { Reunião Anual } \\
33^{\text {a }} \text { Reunião Anual }\end{array}$ & $\begin{array}{l}\text { Veloso (2005); Tomain \& } \\
\text { Lima (2010). }\end{array}$ & $\begin{array}{l}\text { Políticas educacionais contrárias às cotas } \\
\text { evidenciada na representatividade de } \\
\text { professores. }\end{array}$ \\
\hline $\begin{array}{l}28^{a} \text { Reunião Anual } \\
29^{a} \text { Reunião Anual }\end{array}$ & $\begin{array}{l}\text { Miranda (2005), Menin \& } \\
\text { Shimizu (2006). }\end{array}$ & $\begin{array}{l}\text { Políticas de cotas restritas apen as ao grupo } \\
\text { beneficiário (negro). }\end{array}$ \\
\hline $\begin{array}{l}29^{\mathrm{a}} \text { Reunião Anual } \\
32^{\mathrm{a}} \text { Reunião Anual }\end{array}$ & Rosa (2006), Souza (2009). & $\begin{array}{l}\text { Política como uma abordagem culturalista } \\
\text { de subversão de valores discriminatórios }\end{array}$ \\
\hline $\begin{array}{l}31^{\mathrm{a}} \text { Reunião Anual } \\
32^{\mathrm{a}} \text { Reunião Anual }\end{array}$ & Jesus $(2008,2009)$. & $\begin{array}{l}\text { Política como micro-ações a firmativas } \\
\text { cotidianas. }\end{array}$ \\
\hline $34^{a}$ Reunião Anual & $\begin{array}{l}\text { Barbosa \& Lima (2011), } \\
\text { Marques (2011). }\end{array}$ & $\begin{array}{l}\text { Discursos de Políticas de Estado, estruturais } \\
\text { e universais articuladas. }\end{array}$ \\
\hline
\end{tabular}

A síntese dos resultados da pesquisa apresenta os gêneros do discurso, neste caso os Anais das Reuniões Anuais da ANPED, por ano de publicação, agentes enunciadores e enunciados, estes entendidos como dimensão discursiva, os quais não ocorrem a esmo, mas voltados para as relações de poder e apropriado por agentes discursivos, ou seja, alguém que fala para outro alguém. Nesse contexto, os enunciados tomam formas apropriadas de circulação, sejam orais ou escritas, refletem as finalidades específicas de cada contexto socio- comunicativo (Bakhtin 2003, 2010).

Assim, os Anais das Reuniões Anuais da ANPED constituem um gênero reservado a propagação dos discursos, saberes e informação. Sua circulação no site da ANPED permitiu aos seus usuários uma maior e mais efetiva participação na cultura letrada da Política Curricular e Relações Raciais. Em linhas gerais, os Anais possibilitam encontros, debates e discussões, ou seja, possibilitam as mais expressas intenções discursivas a fim de manter estreitos 
contatos entre os diversos campos sociais.

Entre outras intenções discursivas dos Anais, destacam-se alguns enunciados que expressam, de um lado, os percursos de Universidades Federais e Estaduais, nas quais as Políticas Educacionais no tocante às reservas de vagas foram implementadas e, por outro, as experiências de ONGs antirracistas voltadas para a inclusão de alunos negros no Ensino Superior brasileiro. Desta forma concordamos com os argumentos de Silva (2003) quando nos diz:

"Uma instituição, que se disponha a implantar planos de ações afirmativas para a população negra, não pode encará-lo como 'proteção aos desvalidos', segundo pretendem alguns. É preciso que um plano com tais metas incentive a compreensão dos valores da diversidade social, cultural, racial e, nestes valores, busque apoio para orientar suas ações educativas, de formação de profissionais e de responsável pelo avanço das ciências. Sem dúvida, a universidade, ao prever e executar medidas visando à inclusão de grupos até então deixados à margem, inclui-se na sociedade, passa a dela fazer parte e assume compromisso com ela, já que deixa de atender unicamente aos interesses de um único segmento até então privilegiado" (Silva 2003:48).

Desse modo, compreendemos que as adoções de Políticas de Ações Afirmativas partem de uma perspectiva extremamente individual para uma lógica coletiva, pois não se trata mais de "proteção aos desvalidos" pelos efeitos da discriminação e mesmo evitar e prevenir outras manifestações de preconceito.

Quanto às intenções discursivas dos textos relacionados à Lei $n^{\circ} 10.639 / 2003$, estas se configuram como uma conquista para o negro brasileiro e avançam na direção da construção cotidiana de novas relações sociais. Contudo, no decorrer do trabalho, nosso entendimento é de que a Lei $n^{\circ} 10.639 / 03$, se trabalhada dentro da perspectiva da superação do dilema brasileiro (raşa/cor), ainda em trânsito no século XXI, é como incluir sem preterir e integrar, reconhecendo as peculiaridades afrodescendentes, tanto aquelas advindas do processo histórico social singular brasileiro, quanto aquelas que conferem uma identidade particular ao referido grupo.

Assim, a compreensão dos novos sentidos e possibilidade de uma construção democrática que tenha por base o reconhecimento de nossas diferenças étnico-raciais, de inserção no sistema educacional, a qual se impõe pela necessidade de políticas preocupadas com reparações, compensações e ou ações afirmativas (Siss 2002, Veríssimo 2003, Pereira 2007, Souza 2011), que visam assegurar condições de acesso e tratamento igualitário para os negros em todas as esferas da vida social.

Destarte, as pesquisas sobre Educação e Relações Raciais foram ampliadas na última década no Brasil, favorecendo a abertura de espaços de discussões e busca de alternativas para minimizar a discriminação racial e o preconceito nas escolas. Desse modo, concluímos que esses estudos impulsionam o debate sobre a superação do racismo, discriminação e preconceito racial nos diferentes campos sociais.

\section{AGRADECIMENTOS}

Cumpre lembrar que o Estado da Arte sobre Política Curricular e Relações "Raciais" foi um estudo realizado no Curso de Doutorado pelo Programa de Pós-Graduação em Educação da Universidade Federal do Pará (PPGED/UFPA), sob a 
orientação da Prof. ${ }^{a}$ Dr. ${ }^{a}$ Wilma de Nazaré Baía Coelho (PPGED/PPHIST/UFPA). Ressaltamos que os estudos sobre essa temática se consubstanciam nas pesquisas empreendidas pela Orientadora.

\section{NOTAS}

${ }^{1}$ A ANPED foi fundada em 1976 por alguns Programas de Pós-Graduação da Área da Educação. Três anos mais tarde, em 1979 já consolidada como sociedade civil independente, e entidade representativa, a ANPED passa a admitir duas categorias de sócios: os institucionais, integrados pelos Programas de Pós-Graduação em Educação e os sócios individuais, integrados pelos professores, pesquisadores e estudantes de Pós-Graduação em Educação. Vinte e seis anos após a fundação da ANPED foi criado, nessa Associação, o seu $21^{\circ}$ Grupo de Estudos (GE), denominado Relações Raciais/Étnicas e Educação passando, dois anos após, à categoria de Grupo de Trabalho (GT), intitulado Afro-Brasileiros e Educação, GT que congrega pesquisadores e pesquisadoras afro-brasileiros, ou não, cuja produção científica está localizada na área das Relações Raciais e Educação, com ênfase na educação dos Afro-brasileiros (Siss \& Oliveira 2004).

${ }^{2}$ Siss e Oliveira (2004) informam que O GT Relações Raciais/Étnicas e Educação foi fundado na $24^{a}$ Reunião Anual da ANPED com o apoio de mais de quinhentos associados individuais e por inúmeras instituições de pesquisa científica iniciando suas atividades durante a $25^{\mathrm{a}}$ Reunião Anual da ANPED. Ao ser criado, os membros desse GT elegeram as professoras doutoras associadas Iolanda de Oliveira e Maria Lúcia Rodrigues Muller como Coordenadora e Vice-Coordenadora do GT, respectivamente.

${ }^{3}$ Sobre o termo "racial" aspeado ou em itá- lico ver as discussões de Schwarcz (2011) e recentemente publicado em Botelho e Schwarcz (2012). O termo aspeado assume o argumento político de um conceito operante na sociedade brasileira.

${ }^{4}$ A pesquisa baseou-se nos trabalhos de Silva (2008), a qual efetuou análise dos discursos sobre os seguimentos raciais negros e brancos em livros didáticos de Língua Portuguesa para o $5^{\circ}$ Ano do Ensino Fundamental, produzidos entre 1975 e 2003. Pesquisou em 24 bases de dados nacionais, encontrou somente quarenta e quatro referências sobre discurso racista em livros didáticos publicados entre 1987 e 2001. Tomando por base a ANPED, sobre teses e dissertações defendidas entre 1981-1998, encontrou 114 títulos sobre o tema livro didático, dentre esses, somente quatro relacionados ao racismo (estereótipos, preconceito ou discriminação). Já Mainardes (2011) apresenta reflexões sobre as políticas curriculares no contexto da organização da escolaridade em ciclos. Tais reflexões foram formuladas a partir da análise de duas teses e quinze dissertações sobre essa temática, defendidas no período de 2000 a 2009, bem como outras publicações. Ver essa discussão ainda em Oliveira (2004), que apresenta um balanço dos trinta anos da ANPED, assim como, as pesquisas sobre a educação dos afro-brasileiros e o GT-21.

${ }^{5}$ Todos enunciados se enquadram em um gênero, cada esfera da comunicação tem suas formas típicas de enunciado que são os gêneros do discurso (GD). Para Bakhtin (2003:279) "Qualquer enunciado considerado isoladamente é, claro, individual, mas cada esfera de utilização da língua elabora seus tipos relativamente estáveis de enunciados, sendo assim que denominamos gêneros do discurso". Assim, a linguagem é dialógica, formada por enunciados que tem por referência outros enunciados. 
Desse modo, determinados enunciados afirmam ou negam aquele que toma por referência, neste caso, esses enunciados são dotados por elementos ideológicos de várias vozes sociais.

${ }^{6} \mathrm{O}$ conceito de ações afirmativas para o jurista Joaquim Barbosa Gomes implica em: "um conjunto de políticas públicas e privadas de caráter compulsório, facultativo ou voluntário, concebidas com vistas ao combate à discriminação racial, de gênero, com deficiência física ou origem nacional, bem como para corrigir, ou mitigar os efeitos presentes da discriminação praticada no passado tendo por objetivo a concretização do ideal de efetiva igualdade de acesso a bens fundamentais como educação e emprego" (Gomes 2001:27).

'Programa Nacional de Ações Afirmativas (Programa amparado pelo Decreto $\mathrm{N}^{\mathrm{o}} 4.228 / 2002$ que institui, no âmbito da Administração Pública Federal, o Programa Nacional de Ações Afirmativas como uma das políticas de promoção da população negra, implementada com vista a ampliação do acesso de estudantes afro-descendentes ao Ensino Superior (D'Adesky 2006). Lei $\mathrm{n}^{\circ}$ 10.639/2003, Diretrizes Curriculares Nacionais para a Educação das Relações Étnico-Raciais e para o Ensino de História e Cultura Afro-Brasileira e Africana (DCNERER). Parecer CNE/CP 003/2004 (Parecer que visa atender os propósitos expressos na Indicação CNE/CP 6/2002, bem como regulamentar a alteração trazida pela Lei 9394/96 de Diretrizes e Bases da Educação Nacional, pela Lei 10.639/2003, Altera a Lei no 9.394, de 20 de dezembro de 1996, modificada pela Lei no 10.639, de 9 de janeiro de 2003). Lei $\mathrm{n}^{\circ}$ 11.645/2008 (Altera a Lei no 9.394, de 20 de dezembro de 1996, modificada pela Lei no 10.639, de 9 de janeiro de 2003, que estabelece as diretrizes e bases da educação nacional, para incluir no currículo oficial da rede de ensino a obrigatoriedade da temática "História e Cultura Afro-Brasileira e Indígena” (Brasil 2008). Plano Nacional de Implementação das Diretrizes Curriculares Nacionais para Educação das Relações Étnico-Raciais e para o Ensino de História e Cultura Afro-brasileira e Africana (o Plano apresenta por objetivo central colaborar para que todo o sistema de ensino e as instituições educacionais cumpram as determinações legais com vistas a enfrentar todas as formas de preconceito, racismo e discriminação para garantir o direito de aprender e a equidade educacional a fim de promover uma sociedade mais justa e solidária). E, recentemente, o Estatuto da Igualdade Racial (a Lei no 12.288 de 20 de julho institui o Estatuto da Igualdade Racial, alterando as Leis nos 7.716, de 5 de janeiro de 1989, 9.029, de 13 de abril de $1995,7.347$, de 24 de julho de 1985 , e 10.778, de 24 de novembro de 2003).

${ }^{8}$ Ver discussão em Bakhtin (2003).

${ }^{9}$ Ver discussão circunstanciada em Skidmore (1976), Da Matta (1996), Guimarães (1996), Telles (1996), Schwarcz (1993), Coelho et al. (2008), Silva Jr (2000) e entre outros.

\section{REFERÊNCIAS}

Anderson, P. 1995. Balanço do Neoliberalismo, in Pós-neoliberalismo: As Políticas Sociais e o Estado Democrático. Coordenado por E. Sader, pp. 9-23. São Paulo: Paz e Terra.

Apple, M.W. Consumindo o outro: branquidade, educação e batatas fritas, in $A$ escola básica na virada do século: Cultura, política e educação. Organizado por M.V. Costa, pp. 25-43. São Paulo: Cortez, 1996.

Bakhtin, M. (Volochínov). 2010. Marxismo e filosofia da linguagem. São Paulo: Hucitec.

Bakhtin, M. 2003. Estética da criação verbal. 
São Paulo: Martins Fontes.

Barbosa, V.A., \& E.G.S. Lima. 2011. Programa de integração e de inclusão étnico-racial: ações afirmativas na UNEMAT uma questão de (re) educação, in Anais da $34^{a}$ Reunião Anual da Associação Nacional de Pós-Graduação e Pesquisa em Educação. Natal, Rio Grande do Norte.

Barreto, E.S.S. 2000. Tendências recentes do currículo do Ensino Fundamental no Brasil, in Os curriculos do Ensino Fundamental no Brasil. Organizado por E.S.S. Barreto, pp. 4-42. Campinas: Fundação Carlos Chagas.

Botelho, A., \& L.M. Schwarcz (Orgs.). 2012. Cidadania, um projeto em construção: minorias, justiça e direitos. São Paulo: Claro enigma.

(Orgs.) 2011. Agenda Brasileira: temas de uma sociedade em mudança. São Paulo: Companhia das Letras.

Brasil. 2004. Conselho Nacional de Educação. Conselho Pleno. Parecer CNE/ CP 03/2004. Diretrizes Curriculares para a Educação das Relações Étnico-Raciais e para o Ensino de História e Cultura afro-Brasileria e Africana. Brasília, Ministério da Educação. Disponível em www.mec. gov.br/cne. Acesso em 10 dez. 2012.

2008. Ministério da Educação. Lei $\mathrm{n}^{\circ}$ 11.645/2008 (Altera a Lei no 9.394, de 20 de dezembro de 1996, modificada pela Lei no 10.639, de 9 de janeiro de 2003, que estabelece as Diretrizes e Bases da Educação Nacional, para incluir no currículo oficial da rede de ensino a obrigatoriedade da temática "História e Cultura Afro-Brasileira e Indígena".

1996. Ministério da Educação. Lei n. ${ }^{\circ}$ 10.639, de 09.01.03. Altera a Lei ${ }^{\circ}$ 9.394/96 para incluir no currículo oficial da Rede de Ensino a obrigatoriedade da temática História e cultura afro-brasileira;
Diretrizes Curriculares para a Educação das Relações Étnico-Raciais e para o Ensino de História e Cultura Afro-Brasileira.

Burke, P. 2000, História como memória social, in Variedades de história cultural. Editado por P. Burke, pp. 67-89. Rio de Janeiro: Civilização Brasileira.

Canen, A. 2001. Universos culturais e representações docentes: subsídios para a formação de professores para a diversidade cultural. Educação e Sociedade 77:207-227. 1999. Multiculturalismo e formação docente: experiências narradas. Educação e Realidade 24(2): 89-102.

Canen, A. \& A.F.B. Moreira. 2001. Reflexões sobre o multiculturalismo na escola e na formação docente, in Ênfases e omissões no currículo. Organizado por A. Canen, pp. 15-43. São Paulo: Papirus.

Clifford, J. 1977. Itinerarios transculturales. Barcelona: Gedisa.

Coelho, W.N.B. 2009. A cor ausente. Belo Horizonte: Mazza Edições, Belém: Editora UNAMA.

2006. Igualdade e diferença na escola: um desafio à formação de professores. Cronos 7(2):303-309.

2007. Silêncio e cor: relações raciais e a formação de professoras do estado do Pará (1970-1989), in Anais da 30 Reunião Anual da Associação Nacional de Pós-Graduação e Pesquisa em Educação. Caxambu, Minas Gerais.

Coelho, W.N.B. et al. 2008. Concepções político-educacionais excludentes notas em curso, in Raça, cor e diferença: a escola e a diversidade. Organizado por W.N.B. Coelho, \& M.C. Coelho, pp.34-55. Belo Horizonte: Mazza.

Coelho, W., \& M.C. Coelho (Orgs.). 2008. Raça, cor e diferença: a escola e a diversidade. 
Belo Horizonte: Mazza.

D’Adesky, J. 2006. Anti-racismo, liberdade e reconbecimento. - Rio de Janeiro: Daudt.

Da Matta, R. 1996. Notas sobre o racismo à brasileira, in Multiculturalismo e racismo: 0 papel da ação afirmativa nos Estados democráticos contemporâneos. Organizado por J. Souza, pp.34-55. Brasília: Ministério da Justiça.

Dias, L.R. 2005. Quantos passos já foram dados? A questão da raça nas leis educacionais - da LDB de 1961 à Lei 10.639, de 2003, in História da Educação do Negro e outras histórias. Organizado por J. Romão, pp. 49-62. Brasília: Ministério da Educação, Secretaria de Educação continuada, Alfabetização e Diversidade.

Duarte, E.C.P. et al. 2008. Cotas raciais no Ensino Superior. Curitiba: Juruá.

Flick, U. 2004. Uma introdução à pesquisa qualitativa. Porto Alegre: Bookman.

Gatti, B. 1983. Pós-Graduação e Pesquisa em Educação no Brasil: 1978-1981. Cadernos de Pesquisa 44:3-17.

Ginzburg, C. 1989. Mitos, emblemas, sinais: morfologia e história. São Paulo: Cia. das Letras.

Giroux, H.A. 1997. Os professores como intelectuais: rumo a uma pedagogia crítica da aprendizagem. Porto Alegre: Artes Médicas.

Giroux, H.A., \& P. McLaren. 2009. Formação de professor como uma Contra- esfera: pedagogia radical como forma de política cultura, in Currículo, cultura e sociedade. Organizado por A.F. Moreira, \& T.T. Silva, pp. 125-154. São Paulo: Cortez.

Gomes, J.B. 2001. Ação afirmativa \& principio Constitucional da igualdade: o Direito como instrumento de transformação social. A experiência do EUA. Rio de janeiro: Renovar.

2000. O uso da lei no combate ao racismo: direitos difusos e ações civis pú- blicas, in Tirando a mascara: Ensaios sobre o racismo no Brasil. Organizado por A.S.A. Guimarães, \& L. Huntley, pp. 389-409. São Paulo: Paz e Terra.

Gomes, N.L. 2008. A questão racial na escola: desafios colocados pela implementação da Lei 10.639/03, in Multiculturalismo: diferenças culturais e práticas pedagógicas. Organizado por A.F. Moreira, \& V.M. Candau, pp.67-89. Petropólis, RJ: Vozes.

2006. Tempos de lutas: as ações afirmativas no contexto brasileiro. Brasília: MEC/ SECAD,

2003. Cotas étnicas e democratização da universidade pública. Presença Pedagógica 53:55-61.

Gonçalves, L.R.D., \& M.V. Silva. 2005. A questão do negro e políticas públicas de educação multicultural: avanços e limitações, in Anais da $28^{a}$ Reunião Anual da Associação Nacional de Pós-Graduação e Pesquisa em Educaşão. Caxambu, Minas Gerais.

Gonçalves, L.A.O., \& P.B.G. Silva. 2000a. Movimento negro e educação. Revista da ANPED 63:34-48.

2000b. O Jogo das diferenças: O Multiculturalismo e seus contextos. Belo Horizonte: Autêntica.

Guimarães, A.S.A desigualdade que anula a desigualdade: notas sobre a ação afirmativa no Brasil, in Multiculturalismo e racismo: o papel da ação afirmativa nos Estados democráticos contemporâneos. Organizado por J. Souza, pp. 233-242. Brasília: Ministério da Justiça.

Jesus, R.F. 2009. Práticas pedagógicas evidenciam micro-ações afirmativas Cotidianas, in Anais da $32^{a}$ Reunião Anual da Associação Nacional de Pós-Graduação e Pesquisa em Educaşão. Caxambu, Minas Gerais.

2008. Micro-ações afirmativas no cotidiano de escolas públicas, in Anais da $31^{a}$ Reunião Anual da Associação Nacional de 
Pós-Graduação e Pesquisa em Educaşão. Caxambu, Minas Gerais.

Jodelet, D. (Org.). 2001. As representações sociais. Rio de Janeiro: EDUERJ.

Le Goff, J. 1994. Memória, in História e Memória. Editado por J. Le Goff, pp. 423-483. Campinas: Ed. UNICAMP.

Mainardes, J. 2011. A organização da escolaridade em ciclos e as políticas de currículo. Revista e-Curriculum 7:1-20.

Marques, E.P.S. 2011. A manifestação do preconceito e da discriminação racial na Trajetória dos alunos negros bolsistas do PROUNI, in Anais da $34^{a}$ Reunião Anual da Associação Nacional de Pós-Graduação e Pesquisa em Educação. Natal, Rio Grande do Norte.

McLaren, P. 2000. Multiculturalismo crítico. São Paulo: Cortez/Instituto Paulo Freire.

Menin, M.S.S., \& A.M. Shimizu. 2006. Representações sociais de diferentes políticas de ação Afirmativa para negros, afrodescendentes e alunos de Escolas públicas numa universidade brasileira, in Anais da $29^{a}$ Reunião Anual da Associação Nacional de Pós-Graduação e Pesquisa em Educação. Caxambu, Minas Gerais.

Miranda, C. 2005. Narrativas sobre "cotas" em jornais: o híbrido e o grotesco nos discursos de resistência frente à perspectiva afrodescendente de interculturalidade, in Anais da $28^{a}$ Reunião Anual da Associação Nacional de Pós-Graduação e Pesquisa em Educação. Caxambu, Minas Gerais.

Moehlecke, S. 2000. Propostas de ações afirmativas para o acesso da população negra ao Ensino Superior no Brasil, in Educação, racismo e anti-racismo. Organizado por D. Queiroz et al., pp. 69-96. Salvador: Programa A Cor a Bahia/UFBA.

Moscovici, S.A. 1978. Representação Social da Psicanálise. Rio de Janeiro: Zahar.
Oliveira, I. 2004. Trinta anos de ANPED, as pesquisas sobre a educação dos afro-brasileiros e o GT-21: marcas de uma trajetória, in Anais da 24a Reunião Anual da Associação Nacional de Pós-Graduação e Pesquisa em Educação. Caxambu, Minas Gerais.

Pereira, A.M. 2007. "Quem não pode atalhar, arrodeia!": reflexões sobre o desafio da práxis dos educadores dos agentes da Lei 10.639/03, in Anais da $30^{\mathrm{a}}$ Reunião Anual da Associação Nacional de Pós-Graduação e Pesquisa em Educação. Caxambu, Minas Gerais.

Rocha, H.S.C. 2008. A experiência da Lei $n^{\circ}$ 10.639/2003 CEFET-PA Formação inicial e continuada, in Raça, cor e diferença. Organizado por W.N.B. Coelho, \& M.C. Coelho, pp. 56-62. Belo Horizonte: Mazza.

Rodrigues, T.C. 2005. Movimento negro, raça e política educacional, in Anis da $28^{a}$ Reunião Anual da Associação Nacional de Pós-Graduação e Pesquisa em Educação. Caxambu, Minas Gerais.

Rosa, M.C. 2006. Os professores de arte e a inclusão: o caso da Lei 10639/2003, in Anais da 29a Reunião Anual da Associação Nacional de Pós-Graduação e Pesquisa em Educação. Caxambu, Minas Gerais.

Sacristán, J.G. 1998. O currículo: uma reflexão sobre a prática. Porto Alegre: ArtMed.

Santos, S.A. 2005. Açoes afirmativas e combate ao racismo nas Américas. Brasília: Ministério da Educação, Secretaria de Educação Continuada, Alfabetização e Diversidade.

Schwarcz, L.M. 1993. O espetáculo das raças: cientistas, instituições e questão racial no Brasil - 1870-1930. São Paulo: Companhia das Letras.

Silva Júnior, H. 2000. Do racismo legal ao princípio da ação afirmativa: a Lei como obstáculo e como instrumento dos direitos e interesses do povo negro, in Tirando as 
máscaras: ensaios sobre racismo no Brasil. Organizado por A. S. A. Guimarães, \& L. Huntley, pp.53-74. São Paulo: Paz e Terra/SEF. 1998. Anti-racismo - Coletanea de leis brasileiras. São Paulo: Oliveira Mendes.

Silva, P.V. B. 2008. Racismo em livro didático: estudos sobre negros e brancos em livros de Lingua Portuguesa. Belo Horizonte: Autêntica Editora.

Silva, P.B.G. 2003. Negros na universidade e produção do conhecimento, in Educação e Ações Afirmativas: entre a injustiça simbólica e a injustiça econômica. Organizado por P. B. G. Silva, \& V. R. Silvério, pp.43-54. Brasília: Instituto Nacional de Estudos e Pesquisas Educacionais Anísio Teixeira.

Silva, P.B.G., \& V.R. Silvério (Orgs.). 2003. Educação e Ações Afirmativas: entre a injustiça simbólica e a injustiça econômica. Brasília: Instituto Nacional de Estudos e Pesquisas Educacionais Anísio Teixeira.

Silvério, V.R. 2003. Educação e Ações Afirmativas: entre a Justiça simbólica e a injustiça econômica. Brasília: Instituto Nacional de Estudos e Pesquisas Educacionais Anísio Teixeira.

Siss, A. 2003. Afro-brasileiros, cotas e ação afirmativa: razões históricas. Rio de janeiro: Quartet, Niterói: PENESB.

2002. Afro-brasileiros. Políticas de ação afirmativa e educação: algumas considerações, in Anais da $25^{a}$ Reunião Anual da Associação Nacional de Pós-Graduação e Pesquisa em Educação. Caxambu, Minas Gerais.

Skdmore, T.E. 1976. Preto no branco: raça e nacionalidade no pensamento brasileiro. Janeiro: Paz e Terra.

Sovic, L. (2004). Aqui ninguém é branco: hegemonia branca e media no Brasil, in Branquidade: identidade branca e multiculturalismo. Editado por V. Ware, pp. 363-386. Rio de Janeiro: Garamond, 2004.
Souza, M.E.V. 2011. Considerações sobre a (não)implementação da lei 10.639/03 em Escolas públicas do município do rio de janeiro, in Anais da $34^{a}$ Reunião Anual da Associação Nacional de Pós-Graduação e Pesquisa em Educação. Natal, Rio Grande do Norte.

2009. Diálogos possíveis entre concepções de currículo e a Lei 10.639/03, in Anais da $32^{a}$ Reunião Anual da Associação Nacional de Pós-Graduação e Pesquisa em Educação. Caxambu, Minas Gerais.

Telles, E. 1996. Início no Brasil e fim nos Estados Unidos? Revista Estudos Feministas 1:194-201.

Tomain, V.R.R., \& R.C.P. Lima. 2010. Representações sociais de professores do ensino médio sobre cotas para negros na universidade: o mito da democracia racial, in Anais da $33^{a}$ Reunião Anual da Associação Nacional de Pós-Graduação e Pesquisa em Educação. Caxambu, Minas Gerais.

Veloso, G.M. 2005. Cotas na universidade pública - direito ou privilégio?, in Anais da $28^{a}$ Reunião Anual da Associação Nacional de Pós-Graduação e Pesquisa em Educação. Caxambu, Minas Gerais.

Veríssimo, M.V.B. 2003. Educação e desigualdade racial: políticas de ações afirmativas, in Anais da $26^{a}$ Reunião Anual da Associação Nacional de Pós-Graduação e Pesquisa em Educação. Poços de Caldas, Minas Gerais.

. 2004. Política Educacional e Construção de Identidade no Espaço Escolar: crianças negras. in: Anais da $27^{a}$ Reunião Anual da Associação Nacional de Pós-Graduação e Pesquisa em Educação. Caxambu/Minas Gerais.

Ware, V. (2004). Branquidade: identidade branca e multiculturalismo. Rio de Janeiro: Garamond, 2004.

Woodward, K. 2000. Identidade e diferença: 
Santos, R. A.|Silva, R. M. N. B.

uma introducão teórica e conceitual, in Identidade e diferenca: a perspectiva dos estudos culturais. Organizado por T.T. Silva, pp. 7-72. Petrópolis, R.J: Vozes.

Recebido em 31/08/2013

Aprovado em 10/01/2014 